\title{
Era-based Conversion of Aesthetic Taste of Chinese Emphasis on Goodness
}

\author{
Sun Yan ${ }^{1}$ \\ ${ }^{1}$ Faculty of Arts, Southwest University, Chongqing, China \\ Correspondence: Sun Yan, Faculty of Arts, Southwest University, Beibei Direct, Chongqing, China. Tel: \\ 1-861-699-8911. E-mail: cxxs0828@126.com
}

Received: June 12, 2014 Accepted: June 25, 2014 Online Published: July 11, 2014

doi:10.5539/ass.v10n15p206

URL: http://dx.doi.org/10.5539/ass.v10n15p206

\begin{abstract}
An inheritance handed down from age to age is embodied in the process of the development of goodness, a Chinese aesthetic ideology, which belongs to Chinese classical aesthetic category, seemingly, a sense of historical evolution lingers in our minds. Each era has its own aesthetics, as it were, the era itself endows new significance to the aesthetics. Along with the rapid social development, foreign cultures and ideological trend are flooded into China, consequently, Chinese tradition esthetics is subjected to the forceful impact and changed with it. In that case, the inheritance and development of Chinese traditional aesthetic thought seems quite important.
\end{abstract}

Keywords: Chinese, goodness, aesthetic taste, era-based conversion

\section{Introduction}

Chinese aesthetic taste of the emphasis on goodness is long standing as well as the thought itself, which is the product of human society and the crystallization of Chinese cultural development. In remote antiquity, ancestors produced a kind of the so-called Goodness in their minds when they sought the behavior or quality which aimed to benefit for others, themselves, and the society they were living in, and such a thought had been well interpreted in the development of Confucianism, Buddhism and Taoism. Confucian school emphasizes that the intrinsic value generated in a proper relationship among people is the goodness, which has influenced the development of Chinese culture profoundly;. Taoist thought stresses that we shall learn from nature, and we are an integral part of the world, therefore, we shall follow nature laws, and live naturally and truly, then we will live up to the harmonious development among nature, human and living things, which is the so-called goodness. The thought of Goodness Pursuit is also maintained in the Buddhism thought, which aims to detach people from the worldly suffering, be completely indifferent to worldly temptation, and then become a Buddha immediately, all of which are beneficial not only to the one who believe in that, but also to any other people, that is the Zen of goodness. The true essence of goodness is blended with all kinds of cultures, and it updates and transforms itself endlessly. Following the era development, Chinese aesthetic taste of goodness pursuit is endowed with different spiritual essence. Especially, nowadays the economic globalization is developing rapidly, and foreign cultures and ideological trends are flooded into China. Consequently, Chinese tradition esthetics is subjected to the forceful impact and changed with it, in that case, the inheritance and development of Chinese traditional aesthetic thought seems quite important.

\section{Aesthetic Spiritual Essence of Goodness}

A profound cultural connotation and aesthetic implication is necessarily contained in the process of generation and development of an aesthetic category. As a Chinese aesthetic taste, Goodness is such a typical example, which has been the core thought and the spiritual essence of Chinese nation since several thousand years. Influenced by Chinese traditional culture, the connotations of goodness in Confucianism, Buddhism, and Taoism are different respectively. Nonetheless, on the whole, those connotations head for the same tendency, that is, they reflect the inherent spirit of objective things. Therefore, the aesthetic spiritual essence of Chinese goodness mainly lies in several aspects as follows: 


\subsection{The Goodness Refers to the Inherent Law of Objective Things}

Everything in the world is indivisible as one entity, and has its own inherent law, therefore, all things, no matter what it is, nature, society or human, they all live and operate themselves abiding by their inherent laws, and such inherent laws are objective facts independent of man's will, operating and developing themselves in accordance with their inner characteristics and basic orders. Socrates claimed that virtues in everything, such as human bodies, soul, or other living things, could not embodied arbitrarily or occasionally, but obtained through orders and proper arrangements suitable for each thing. Virtues in everything are arrangements with regularity and order, therefore, the appearance of such orders suitable for the thing makes anything possess the spirit of goodness." (Wang, 1993) It is thus clear that, as for objective things, the goodness is arranged in order, and is the inherent law with an objective existence, as for human being, the goodness refers to the inherent essence of human, that is, the aesthetics within. The inherent law of things is invisible and unable to be touched, however, "the law of goodness" hides within things, which supports the framework of the entity, and constitutes the inner harmony of things' development. In Chinese traditional aesthetics, "the law of goodness" breeds in the aesthetic thought in the form of implicit category, develops and transforms orderly its profound influence through various aesthetic thought, consequently, the law of goodness can be felt easily by people.

\subsection{Goodness Is a Standard to Measure the Value Orientation}

The value orientation is a spiritual pillar to support human's life, which determines human's thoughts and manners of behavior, therefore, it leads human's life to a correct direction. Following the development of human civilization, people's value orientation has been changed in the modern society, but some limitations exist necessarily, for example, people take one-side pursuit of material benefits, spirit boosting and high work efficiency, etc. Consequently, the human subjective consciousness is contaminated by utilitarianism and lead into a lost. The fact that human has fell into a mental predicament fails to be changed by the development of science and technology, but the establishment of correct value orientation and the quintessence of the pursuit of goodness will do. Socrates claimed that goodness can make things become beneficial and useful main centers, and he ever pointed out clearly that anything beneficial to people is the so-called goodness. He even said that all knowledge about goodness can be regarded as the knowledge about human's interests, and all behaviors living up to happiness without pains are good behaviors, specifically, the goodness and the benefits(Wang,1993). Socrates objected to distort correct value orientations to meet private emotion and desires, which he believed was not the real interest. The real interest shall satisfy the demand of soul, that is, the pursuit of wisdom, in other words, the goodness itself. The goodness is the highest goal of human's social activities sought in social practice, therefore, the correct application of goodness will be beneficial for us to choose correct practice targets and methods to reach the content and effect specified in practice. Aesthetician Cai Yi held that goodness is the social beauty, which is the standard to measure human's value. Goodness has shaped colorful social beauty in every aspect of our social life; embodied firstly in the process of human practice of remaking the nature and the society, secondly, embodied in the products of practice activities, and actually, goodness is the core of social beauty. She pointed out that the so-called beautiful woman was not only good-looking in appearance, but also well qualified in her virtue, moreover, the latter is what it is called social beauty; the beautiful thing may not possess the connotation of goodness, but goodness must be beautiful, so to speak, goodness is a kind of beauty, that is, the social beauty (Cai, 2001). As a standard to measure the value orientation, whichever it is analyzed from, aesthetics, philosophy, or ethics, the inner spirit of subject embodied in social life is emphasized, and such an inner spirit is an important safeguard of harmonious coexistence among human, human and society, human and nature.

\subsection{Goodness Is a Unification of Truth, Goodness and Beauty}

Which is the ideal state of human knowledge and the highest goal of human practice, and it is an important part of aesthetic thoughts. Historically, studies on truth, goodness and beauty has been started in China since 6th Century B.C.. Guoyu (an Ancient Chinese historical book) mentions that if we describe something as a beautiful object, it shall be free from deficiency in all ways. Confucius summarized and outlined predecessors' ideas, and claimed that only the beauty in the shape of sensibility and the goodness of moral principles are united that can the highest ideal be reached as good as it gets; with the viewpoint of dialectics, Lao-Tz revealed the opposition and the unity between beauty and urgliness, goodness and vice; Chuang-Tse took truth as an entry point, and demonstrated the fundamental characteristics of the goodness of nature. Beauty stems from goodness, and the interpretation of truth is realized by goodness; the dialectical relationship of truth, goodness and beauty comes into being in the complementary process of aesthetic thought of Confucianism and Taoism. Ancient philosophers thoughts impacted profoundly on the development of Chinese aesthetic thoughts. In the west, Pythagoras in ancient Greek claimed that beauty and goodness is a combination of harmony; Socrates, the Father of moral 
philosophy called by Lenin, emphasized that virtue is knowledge, and he believed that the so-called knowledge is about goodness, which is eternal and universal; Plato called the knowledge Socrates interpreted as the Idea, and he made goodness superior to all kinds of ideas, that is, the highest idea; both Augustine and Thomas Aquinas combined truth, goodness and beauty with the theology perfectly, and they claimed that only God is the source of truth, goodness, and beauty. Throughout the east and the west philosophy thoughts, we see that goodness not only belongs to the moral category, but also the categories of aesthetics, ethics, ontology and epistemology; goodness reveals the essence and the inner order of things by means of logical thought. The relationship of dialectical unity upholds that truth, goodness and beauty have the same essence, and cannot be independent and divisible, in other words, they are inherently correlated and coherent, which is the unity in a low sense; secondly, the three thoughts have their own peculiarities with a mutual complementation, constituting an integral picture of achievement by human activities, which is a unity in a middle sense; thirdly, the three thoughts are mutually inter-infiltrated, integrated and interpenetrated, in which goodness contained the elements of truth and beauty, meanwhile, the element of goodness exists in truth and beauty, but they cannot be divided completely, which means the goodness is the core, and it is the unity of truth, goodness and beauty, that is, a unity in the highest level.

Goodness is the most fundamental moral concept and the most important aesthetic category, and its substance is to seek a harmonious and unified basic law that is abided by heaven, earth and man, and kept constantly in all things on earth. Goodness adequately nourishes a kind of inner spirit of the subject, and intensively reflects the ultimate aim and the spirit of human practical activities, which is a high generalization on the mission shouldered on human in the practical activities. The unceasing pursuit of the goodness is the impetus on the constant development of human demands and the continuous improvement of practical activities.

\section{The Era-based Conversion of Aesthetic Thoughts of Goodness}

An inheritance handed down from age to age is embodied in the process of the development of Chinese aesthetic ideology - goodness, which belongs to Chinese classical aesthetic categories, seemingly, a sense of history evolution lingers in our minds. The standards that measure whether the aesthetic theory is improving forward not only relies on the quality of artistic work, but also the pace of era development. Each era has its own aesthetics, as it were, the era itself endows a new significance to the aesthetics. Time-to-space conversion from classics to modernity has its inner underlying cause, or else, such a conversion can only be an accidental event, and lacks the subsistent significance and value. The conversion of Chinese classical aesthetic thought goodness from classics to modernity is not only a kind of inherence, but also a kind of development, which is closely related to the mechanism such as personal constraints, social control, etc.

How shall we establish the two kinds of mechanism? Three prerequisites must be needed primarily to establish the personal restraint mechanism. Firstly, the beauty of goodness shall be manifested by the inner sincerity. Lu Jiuyuan, a notable Neo-Confucianism scholar in Chinese Song Dynasty said, "if one serves the public and does the good, it implies that his heart is in a good conscience, however, if one does the harm to the public and goes for privacy, it implies that his heart is tangled by evil. Serving the public and doing the good will create an atmosphere of harmony and cooperation, and that is the blessing from God, however, doing the harm to the public and going for privacy will create an atmosphere of dissension and offence, and that is the disaster from evil. Harmony and cooperation is what people are expected, but dissension and offence is what people are disgusted. The street in my city hasn't been repaired for a long time, and the passerby hated that very much. Under such a circumstance, if one determines to contribute to the maintenance, such as donation, labor strength, etc. and spares no effort to repair it, he is really a standout serving the public and do the good, which is owing to one's heart in a good conscience ( $\mathrm{Lu}, 1980)$ ". Lu claimed that due to the heart in a good conscience, i.e. the benevolence, one will serve the public and do the good for the public. The best way to nourish the soul is sincerity, and only that can one better benefits to others. Comparing between Cheng and Zhu's Neo-Confucianism and $\mathrm{Lu}$ and Wang' heart-mind theory, we will find that ways to understand sincerity is different, the former highlights the thought-cast to understand goodness in heart; the latter experiences goodness of thing in itself by virtue of the subject, to manifest goodness. Although the two tread different paths to understand goodness, both of them managed to illuminate the essence of the inner goodness, that is, "scholars shall be sincere, without sincerity, goodness disappear, and one cannot be called a man of noble character. If one is not sincere in studies, what he gets will be mixed; if one is not sincere in do things, he will be in failure (Cheng, 1981)". It is thus clear that, as for the ancients, the way to become a man with goodness is "an eye of sincerity to know the inner goodness, and a behavior of sincerity to do the philanthropic act". Up to this day, such a method is still worth learning and referring. Secondly, checking erroneous ideas at the outset, praising virtue and preventing vice. Forefathers said "people often neglect the tiny beneficence and vice. Ordinary people 
flatter themselves that the tiny vice in their daily speech and behavior is insignificant, however, actually such an insignificance is the most catastrophic. People always think that their abandonment and stupid behavior is not harmful, however, a severe wickedness is gradually shaped unconsciously (Chen, 1979)". Although the tiny and slight behavior of good and evil is neglected easily, it will lead to a serious aftermath, just like many sands piled up will make a mountain, and little drops of water collected will make an ocean. Zen Master Zhenke in Late-Ming Dynasty ever said that one maybe not aware of the goodness, accumulated by doing the good, but the generous blessing will arrive unconsciously. Similarly, one may be not aware of the accumulated vice, but the serious disaster will arrive unconsciously. The disaster results from the neglect on the tiny sign, however, the blessing will grow gradually owing to the emphasis on goodness and experience it diligently ( $\mathrm{Si}, 2000)$. It is thus clear that whether it is the disaster or the blessing, it always develops gradually. The tiny goodness without awareness will be accumulated into a generous blessing, and the tiny vice without awareness will be accumulated into a serious disaster. Therefore, we shall set strict demands on ourselves, and do the good once a day; give up the idea that it doesn't matter to practice any trivial vice, and it is not worth doing any tiny goodness, only realizing that can we live up to a perfect goodness, just like the grass in spring season, we maybe not find its growth only by our visual inspection, however, it is actually growing day by day. Thirdly, we shall be good at learning something beneficial to the goodness, and the correction of our vice. Sanzijing (an Ancient Chinese $\mathrm{ABC}$ book) mentions that, men at their birth are naturally good, and their nature is much the same, however, their habits become widely different due to the acquired disposition. Wang Anshi, an eminent Politian in Song Dynasty elaborated in his studies on human nature that if one had the habit of goodness, we called him a wise man; if one had the habit of vice, we called him a foolish man; if one had the mixed habit of goodness and vice, we cauld call him a common man. Therefore, the good virtue of goodness is cultivated by working hard and being adept in learning. The litterateur Yang Xiong in the Western Han Dynasty ever said that if the gentleman studied hard to strengthen his weakness and wipe off his vice, he would almost live up to the high standard (Liu, 1996). According to Yang, if one hopes to cultivate his goodness, he shall learn how to get it, moreover, he shall do the good as quickly as the wind blowing, and correct the vice as fiercely as the thunder. We find out that the thunder and the wind bring out the power in each other, similarly, doing the good quickly will reduce the vice less and less, and determining to correct the vice will make people kind-hearted more and more (Chen, 1983). Doing the good and correcting the vice are important ways to cultivate goodness, both of which complement each other. By this token, only possessing the three prerequisites above that we will own the mellow goodness virtue.

Secondly, by virtue of the personal restraint mechanism, an effective social control mechanism is established. Along with the social development, the material life and spiritual life become more and more advanced, consequently, the common defect of human nature reveals and outbursts naturally, and human deep-rooted bad habits become visible. In order to make the society develop more orderly, a kind of virtue culture shall be applied and spread, that is, goodness. The shape and development of goodness, on the one hand, needs the positive guidance and publicity, on the other hand, relies on the positive instruction against the evil. Only encouraging and advocating the goodness, the insistent pursuit of goodness can be featured in human thoughts, and the human guided to pursue the goodness. Along with the social development, foreign cultures are flooded into China, consequently, the standards that people measure the good and evil are changed. Specifically, they harm others to benefit for themselves, cheat and plunder others, or practice fraud, etc, all of which are the ways biting anyone including themselves, through such ways to judge the good and evil existing in the society, as a result, the interpretation of the goodness is subjective and one-sided. The existence and development of such phenomenon become more and more violent, which inevitably causes certain social contradictions and conflicts, and impacts on social harmonious development. Therefore, it is worth thinking how to fulfill the theory that man is an integral part of nature to shape a good cultural atmosphere in the society, and the corresponding solution is to enlarge the propaganda effect of praising goodness and restraining the evil, guide people to normalize and control themselves in accordance with the nature of goodness, and deal with the relationship between the human and the society, the individual and others, the human and the nature. Lu Jiuyuan in Song Dynasty ever profoundly understood that if people's custom in one country possessed the growing goodness and the decreasing vice, it would indicate that the country was managed in order, however, the opposite case would indicate that would the country was managed in disorder ( $\mathrm{Lu}, 1980)$. The so-called people's custom refers to the social cultural atmosphere. Therefore, a social cultural atmosphere that praises goodness and restrains the evil has an important reference and historical significance to the country management and social stability.

To sum up, the harmonious goodness will obtain a modern conversion and reconstruction only by the interaction between the inside and the outside mechanism. Under the circumstances of modern society, an improved conversion mechanism shall be established for Chinese traditional aesthetic thoughts, and then the traditional 
aesthetic thought will be inhered and developed; the reconstruction and application of the harmony within goodness in the aesthetic category conforms to the contemporary harmonious society, which is an important measure to inherit traditional aesthetic thoughts.

\section{Conclusion}

In Chinese traditional culture, as one of the core categories in classical philosophy and aesthetics, "goodness" has experienced the historical process of inoculation, germination, formation and development, so a complete and unique theoretical system has been formed. Different schools in Chinese ideological history, especially the three pillars of Chinese philosophy which are Confucianism, Taoism and Buddhism, have all expressed their pursuit and yearning for the aesthetic spirit essence of "goodness".

At present, though human society develops rapidly, no changes happen to the essence of the three aesthetic spirits including "inherent law of objective things", "criterion of measuring value orientation" and "unification of the true, the good and the beautiful" possessed by "goodness". However, with acceleration of living tempo, update of ideology, whirl of the commodity economy tide, and strengthening of international exchange, various aesthetic ideas have permeated into our life gradually. As a result, people's aesthetic value orientation becomes diversified, and their aesthetic taste of advocating "goodness" presents an unstable state. Specifically speaking, great differences and diversified trend are reflected in people's pursuit for beauty and value judgment, such as money worship of "money first" including corruption, waste, gutter oil, golden rice, Aldicrab, and "injury feigning". People's aesthetic taste has no unified keynote and fixed aesthetic target, such as rapid increase of indoors men and indoors women, network copy replacing the production of innovation, and the ruffian behaviors of the official lings, Rich $2 \mathrm{G}$, and children of rural labors. People tend to pursue more physical pleasure while ignore the spiritual enjoyment. The appearance of fast-food culture greatly affects generation of people's aesthetic taste and meanwhile restricts the progress and improvement of human society.

Therefore, the author gained the following conclusions after analysis: firstly, by analyzing the aesthetic taste of Chinese nation, we find that with transformation of the society and progress of the era, the spiritual outlook presented by Chinese traditional esthetics suffers an eclipse. The aesthetic taste of advocating "goodness" plays an indispensable role in the historical course of maintaining social stability, promoting social progress, and driving social development. Secondly, faced with frequent appearance of bad situations in the society, we advocate treating "goodness" as the criterion of measuring value orientation, so as to arouse people's goodness in heart and complement the reality of mixing goodness with evilness. We must shoulder the historical mission of inheriting Chinese traditional aesthetic thought and reviving the national cultural spirit. Thirdly, we should not repeat the old disastrous road of "seeking roots" and revive an old dream. Instead, we need to stand at the height of the 21 st century and reconstruct the spiritual home of our people. As Zong Baihua says, "Can we restore ourselves and our souls from this materialistic world view, so as to prevent ourselves from falling into the nothingness of reason or becoming slaves of materials? Can we harvest the meaning of life in the rich personality life that is the life of love?" (Zong, 2012). Fourthly, we can tactfully utilize the individual and social mechanisms. For instance, we may establish training classes of traditional culture facing the society and launch large public benefit activities that enter the campus and grass roots. This can break and surpass the restraint of reality and utility against human heart to some degree. Besides, people will consciously remove the lowness and profaneness in human nature, and break away from ugliness. In this way, they will become kind, and human nature will gain more significance and value.

In short, this paper systematically studied generation and development of China' aesthetic taste from all perspectives, and combined it with excellent achievements of Western aesthetics to realize new theoretical innovation. The important task that should be completed by us now is to make Chinese traditional aesthetic thought and the national cultural spirit of China bloom perfectly and to better inherit it.

\section{Reference}

Chen, Q. (1979). Chen Que Collected Works. Instructions for Children: No. 17 Volume (p. 43). Beijing: Zhonghua Book Company.

Lu, J. (1980). Lu Jiuyuan Collected Works: No. 20 Volume (pp. 124, 229). Beijing: Zhonghua Book Company.

Cheng, Y., \& Cheng, Y. (1981). Cheng Ying \& Chengyi's collected Works: No. 8 Volume (p. 56). Beijing: Zhonghua Book Company.

Chen, M. (1983). Studies on Zhouyi: No.5 volume (p. 129). Shanghai: Shanghai Ancient Book Publishing House.

Wang, Z., Chen, C., Bao, L., \& Zhang, X. (1993). History of Greek Philosophy: No. 2 Volume (pp. 442-444). Beijing: People's Publishing House. 
Liu, S. (1996). Collation and Annotation on Taixuan (p. 67). Wuhan: Central China Normal University Publishing House.

Si, K. (2000). Collections not included in Imperial Collection of Four Divisions. Beijing: Beijing Publishing House.

Cai, Y. (2001). Cai Yi Collected Works (pp. 329-343). Beijing: China Literary Federation Publishing House.

Chen, W. (2007). 21 Instructions on Chinese Classical Aesthetics. Changsha: Hunan Education Press.

Ye, L. (2009). Elements of Aesthetics. Beijing: Peking University Press.

Hu, J. (2010). Aesthetics. Beijing: Peking University Press.

Zong, B. (2012). Complete Works of Zong Baihua (Version 2). Hefei: Anhui Education Publishing House.

\section{Copyrights}

Copyright for this article is retained by the author(s), with first publication rights granted to the journal.

This is an open-access article distributed under the terms and conditions of the Creative Commons Attribution license (http://creativecommons.org/licenses/by/3.0/). 